\title{
A Time Series Analysis of Air Pollution and Preterm Birth in Pennsylvania, 1997-2001
}

\author{
Sharon K. Sagiv, ${ }^{1}$ Pauline Mendola, ${ }^{2}$ Dana Loomis, ${ }^{1}$ Amy H. Herring, ${ }^{3}$ Lucas M. Neas, ${ }^{2}$ David A. Savitz, ${ }^{1}$ and \\ Charles Poole ${ }^{1}$
}

${ }^{1}$ Department of Epidemiology, University of North Carolina at Chapel Hill, Chapel Hill, North Carolina, USA; ${ }^{2} \mathrm{National} \mathrm{Health} \mathrm{and}$ Environmental Effects Research Laboratory, Office of Research and Development, U.S. Environmental Protection Agency, Research Triangle Park, North Carolina, USA; ${ }^{3}$ Department of Biostatistics, University of North Carolina at Chapel Hill, Chapel Hill, North Carolina, USA

Preterm delivery can lead to serious infant health outcomes, including death and lifelong disability. Small increases in preterm delivery risk in relation to spatial gradients of air pollution have been reported, but previous studies may have controlled inadequately for individual factors. Using a time-series analysis, which eliminates potential confounding by individual risk factors that do not change over short periods of time, we investigated the effect of ambient outdoor particulate matter with diameter $\leq 10 \mu \mathrm{m}\left(\mathrm{PM}_{10}\right)$ and sulfur dioxide on risk for preterm delivery. Daily counts of preterm births were obtained from birth records in four Pennsylvania counties from 1997 through 2001. We observed increased risk for preterm delivery with exposure to average $\mathrm{PM}_{10}$ and $\mathrm{SO}_{2}$ in the 6 weeks before birth [respectively, relative risk $(\mathrm{RR})=1.07 ; 95 \%$ confidence interval $(\mathrm{CI}), 0.98-1.18$ per $50 \mu \mathrm{g} / \mathrm{m}^{3}$ increase; $\mathrm{RR}=1.15 ; 95 \% \mathrm{CI}, 1.00-1.32$ per $15 \mathrm{ppb}$ increase], adjusting for long-term preterm delivery trends, co-pollutants, and offsetting by the number of gestations at risk. We also examined lags up to 7 days before the birth and found an acute effect of exposure to $\mathrm{PM}_{10} 2$ days and 5 days before birth (respectively, $\mathrm{RR}=1.10 ; 95 \% \mathrm{CI}$, $1.00-1.21 ; \mathrm{RR}=1.07 ; 95 \% \mathrm{CI}, 0.98-1.18)$ and $\mathrm{SO}_{2} 3$ days before birth $(\mathrm{RR}=1.07 ; 95 \% \mathrm{CI}$, 0.99-1.15), adjusting for covariates, including temperature, dew point temperature, and day of the week. The results from this time-series analysis, which provides evidence of an increase in preterm birth risk with exposure to $\mathrm{PM}_{10}$ and $\mathrm{SO}_{2}$, are consistent with prior investigations of spatial contrasts. Key words: air pollution, environmental epidemiology, particulate matter, pregnancy, preterm birth, sulfur dioxide. Environ Health Perspect 113:602-606 (2005). doi:10.1289/ehp.7646 available via $h t t p: / / d x$.doi.org/ [Online 2 February 2005]

Preterm delivery can lead to neonatal mortality as well as an array of infant morbidities that range from pulmonary to neurologic outcomes (Martin et al. 2002). The prevalence of preterm delivery was $11.6 \%$ in the United States in the year 2000 (Centers for Disease Control and Prevention 1999; Martin et al. 2002). Fewer than half of preterm births in developed countries can be attributed to known risk factors (Berkowitz and Pepiernik 1993; Kramer 1987). There is a clear need to explore causes of preterm delivery that might be modifiable, such as environmental exposures.

A small number of previous studies have explored the association between criteria air pollutants-carbon monoxide, nitrogen dioxide, ozone, sulfur dioxide, particulate matter with diameter $\leq 10 \mu \mathrm{m}\left(\mathrm{PM}_{10}\right)$, and in some cases total suspended particulates (TSP) and preterm delivery by examining spatial exposure contrasts between individuals based on the place of residence at birth (Bobak 2000; Liu et al. 2003; Maroziene and Grazuleviciene 2002; Ritz et al. 2000; Xu et al. 1995). Although these studies varied with regard to the pollutant(s) evaluated, the most consistent findings reported were for positive associations between $\mathrm{PM}_{10} / \mathrm{TSP}$ and $\mathrm{SO}_{2}$ late in pregnancy and preterm delivery (Bobak 2000; Liu et al. 2003; Ritz et al. 2000; Xu et al. 1995).
Relying on spatial analyses comparing high-exposure areas with low-exposure areas, previous studies have been subject to the effects of confounding by individual risk factors, such as maternal smoking and unmeasured or unknown risk factors. To date, no study has looked at the effect of air pollution on preterm delivery using a time-series analysis with exposure contrasts over time rather than space. Time-series analysis removes the influence of covariates that vary across individuals but not within individuals over short periods of time.

We investigated the associations during the years 1997 through 2001 of risk for preterm delivery with average concentrations of ambient outdoor $\mathrm{PM}_{10}$ and $\mathrm{SO}_{2}$ during the 6 weeks preceding birth in four Pennsylvania counties selected for their contrasting $\mathrm{PM}_{10}$ and $\mathrm{SO}_{2}$ distributions. We also explored a possible acute effect of these pollutants by narrowing the exposure window to a 1-day interval before birth, with daily lags ranging from 1 to 7 days.

\section{Materials and Methods}

Study population. The study population consisted of all live singleton births whose mothers resided in four Pennsylvania counties (Allegheny, Beaver, Lackawanna, and Philadelphia) and for whom birth certificates were filed with dates of birth between 1 January 1997 and 31 December $2001(n=187,997)$. These counties were chosen for their diverse mix and wide range of pollutants. Births were restricted to gestational ages within the range of 20-44 weeks because births at $<20$ gestational weeks are rarely viable and births are usually induced before 44 weeks of gestation.

Exposure estimation. We obtained ambient outdoor air pollution monitoring data for the four study counties over the 5-year study period (20 November 1997 through 30 December 2001) from the U.S. Environmental Protection Agency (EPA) Air Quality System (AQS). Daily mean values were computed for the two air pollutants of primary interest $\left(\mathrm{PM}_{10}\right.$ and $\left.\mathrm{SO}_{2}\right)$ and for those considered co-pollutants $(\mathrm{CO}$, $\mathrm{NO}_{2}$, and $\left.\mathrm{O}_{3}\right) \cdot \mathrm{PM}_{10}$ was collected hourly for three of the counties using a tapered element oscillating microbalance sampler, and every sixth day in one county using a high-volume air sampler system. We used public access data from EPA's AQS and did not directly measure pollutants with these samplers. Thus we do not know the manufacturer for the TEOM and high-volume air samplers. Three counties had multiple monitoring stations for each pollutant; a single average countywide daily pollutant value was computed for each of these counties.

Because the acute effects analysis assessed shorter-term changes in pollution levels, we considered covariates such as temperature and dew point temperature (a measure of relative

Address correspondence to S. Sagiv, Channing Laboratory, 181 Longwood Ave., Boston, MA 02115 USA. Telephone: (617) 525-4210. Fax: (617) 5252578. E-mail: sharon.sagiv@channing.harvard.edu

This work was supported by National Health and Environmental Effects Research LaboratoryDepartment of Environmental Sciences and Engineering Cooperative Training in Environmental Sciences Research, EPA CT826513. A.H.H. and C.P. were supported by National Institute of Environmental Health Sciences Center Grant P30ES10126.

This research has been supported in part by the U.S. Environmental Protection Agency. It has been subjected to review by the National Health and Environmental Effects Research Laboratory and approved for publication. Approval does not signify that the contents reflect the views of the agency, nor does mention of trade names or commercial products constitute endorsement or recommendation for use.

The authors declare they have no competing financial interests.

Received 7 October 2004; accepted 2 February 2005. 
humidity), which also change over short periods of time. These meteorologic data were obtained from the National Weather Service (NOAA/NCDC 2003).

Outcome assessment. Gestational age was computed as the number of weeks between the date of the last menstrual period (LMP) and the date of birth. For birth records missing the date of the LMP, the clinical estimate of gestation was used. Eligible births with gestational ages $<36$ weeks were considered preterm. Counts of preterm births were tallied for each day during the 5-year observation period.

Statistical analysis. We conducted a Poisson regression analysis, which followed $\mathrm{PM}_{10}$ and $\mathrm{SO}_{2}$ levels and counts of preterm births jointly over time. Preterm births were measured as a daily count of events assumed to be independent and random. The Poisson model was selected because these counts were small on any given day. Because days of observation were the units of analysis, exposure gradients were measured with reference to time rather than to other individuals.

Covariates in the final models, including co-pollutants, long-term trends in preterm birth, and weather (temperature and dew point temperature), were included a priori because of their established temporal relationship with air pollution in the previous literature and their likely associations with the air pollutants of interest. Previous studies also suggest a

Table 1. Demographics of the study population ${ }^{a}$ $(n=187,997)$ of births in four Pennsylvania counties, 1997-2001.

\begin{tabular}{lc}
\hline Variable & No. (\%) \\
\hline Preterm births (<37 weeks) & $21,450(11.4)$ \\
Maternal age (years) & $690(0.4)$ \\
$<15$ & $24,737(13.2)$ \\
$15-19$ & $43,096(22.9)$ \\
$20-24$ & $48,515(25.8)$ \\
$25-29$ & $44,823(23.8)$ \\
$30-34$ & $21,777(11.6)$ \\
35-39 & $4,325(2.3)$ \\
$\geq 40$ & $34(0)$ \\
Unknown & \\
Maternal race & $111,084(59.1)$ \\
White & $66,022(35.1)$ \\
African American & $7,324(3.9)$ \\
Asian & $1,096(0.6)$ \\
Other & $2,471(1.3)$ \\
Unknown & \\
Maternal education (years) & $3,515(1.9)$ \\
0-8 & $29,247(15.6)$ \\
9-11 & $64,353(34.2)$ \\
12 & $39,328(20.9)$ \\
13-15 & $27,862(14.8)$ \\
$\geq 16$ & $23,692(12.6)$ \\
Unknown & \\
Marital status & \\
Married to father & $97,216(51.7)$ \\
Not married to father & $90,617(48.2)$ \\
Unknown & $164(0.1)$ \\
\hline
\end{tabular}

alncludes all live singleton births with a nonmissing gestational age estimate on the birth certificate in the range of 20-44 weeks, excluding births with geocoded maternal address outside of the four study counties. consistent seasonal pattern for preterm birth (Cooperstock and Wolfe 1986; Keller and Nugent 1983; Matsuda and Kahyo 1992).

Mean 6-week analysis. We used daily pollutant levels in each county to compute the mean air pollution concentration value for the 6-week period preceding each day of observation. To incorporate county-level information, we used a multivariable mixed-effects model with a random intercept for each county. We controlled for long-term preterm birth trends and mean 6-week level of co-pollutants (CO, $\mathrm{NO}_{2}$, and $\mathrm{SO}_{2}$ in the $\mathrm{PM}_{10}$ analysis and $\mathrm{CO}$, $\mathrm{NO}_{2}$, and $\mathrm{PM}_{10}$ in the $\mathrm{SO}_{2}$ analysis). Because the number of births in the population varies by season, we included a term in the timeseries model to offset the total number of gestations in the population at risk for preterm birth on each day during the study period.

We examined county-specific long-term trends for preterm birth using LOESS plots, which are nonparametric, locally weighted regression smoothers. Parametric functions were fit in the final models, however, to achieve more conservative standard errors yet account for long-term trends in a flexible manner (Dominici et al. 2002). To control for these trends in the multivariable model, we fit spline functions with knots placed at points that parsimoniously simulated the LOESS smoothing curves. Various spline functions, including linear, quadratic, and cubic splines, were evaluated, and the function that provided the best fit was retained.

Daily acute effect analysis. For the analysis of the acute effect of $\mathrm{PM}_{10}$ and $\mathrm{SO}_{2}$, we investigated risk for preterm birth in relation to levels of pollutants for a 1-day exposure window with lags from 1 to 7 days before birth. In addition to adjusting for long-term trends, we controlled for daily levels of co-pollutants and other shortterm time-varying covariates, including temperature, dew point temperature, and day of the week. The number of gestations at risk for preterm birth was used as an offset. We explored different exposure windows and lags for both temperature and dew point temperature; because associations between these covariates and preterm birth have not been reported in the literature, we chose the window and lag combination with the best fit, determined by Akaike's Information Criterion (Akaike 1973). Linear relationships of temperature and dew point temperature with preterm birth were improbable; we therefore used parametric spline functions to represent these covariates.
We estimated relative risks (RRs) and 95\% confidence intervals (CIs) for 6-week and daily acute exposure (for each of the 7 days before birth) to $\mathrm{PM}_{10}$ and $\mathrm{SO}_{2}$. Pollutants were modeled as continuous variables, and estimates were reported for exposure increments of $50 \mu \mathrm{g} / \mathrm{m}^{3}$ in $\mathrm{PM}_{10}$ and $15 \mathrm{ppb}$ in $\mathrm{SO}_{2}$. These ranges were chosen because they were consistent with previous studies yet still within the range of exposure for our study; this facilitated the direct comparison of our results with the existing literature. The possibility of a nonlinear dose-response relationship between pollutants and preterm birth was also assessed by categorically dividing pollutant concentration into quarters. RRs and 95\% CIs were estimated for each quarter.

Approval for this research was obtained from the Committee on the Protection of the Rights of Human Subjects at the Biomedical Institutional Review Board of the University of North Carolina at Chapel Hill's School of Medicine.

\section{Results}

Descriptive statistics. A total of 200,253 birth records were available for the four counties between 1997 and 2001. For 36,839 birth records missing the date of the LMP, we used the clinical estimate of length of gestation; secondary analyses showed that inclusion of these births did not meaningfully change the estimated associations but did enhance precision, and we therefore included these births in the final analyses. We excluded 677 births to mothers whose geocoded residence at delivery was outside the four study counties and 6,322 multiple births. An additional 5,257 births with gestational ages outside the range of 20-44 weeks were excluded. After these exclusions, 187,997 births (94\% of the total) remained. Table 1 shows the demographic characteristics of this final study population. The exclusions did not substantially change the distribution of the demographic characteristics (results not shown).

There were 7,304 observation days for the four counties over the 5 -year study period. A total of 21,450 preterm births occurred over the entire study period. Counts ranged from 0 to 17 preterm births per day, with a mean of approximately 3 preterm births per day and a median of 2 preterm births per day. Data for 6-week and daily $\mathrm{PM}_{10}$ and $\mathrm{SO}_{2}$ are displayed in Table 2. Daily levels of $\mathrm{PM}_{10}$ and $\mathrm{SO}_{2}$ were positively correlated (Pearson correlation

Table 2. Exposure statistics during the 5-year study period (1997-2001) for four counties in Pennsylvania.

\begin{tabular}{lcccr}
\hline Exposure & $\begin{array}{c}\text { No. of } \\
\text { observations }\end{array}$ & Range & Mean \pm SD & Median \\
\hline 6-week $\mathrm{PM}_{10}\left(\mu \mathrm{g} / \mathrm{m}^{3}\right)$ & 5,851 & $8.7-68.9$ & $27.1 \pm 8.3$ & 26.0 \\
Daily PM $_{10}\left(\mu \mathrm{g} / \mathrm{m}^{3}\right)$ & 4,204 & $2.0-156.3$ & $25.3 \pm 14.6$ & 21.6 \\
6-week $\mathrm{SO}_{2}(\mathrm{ppb})$ & 7,304 & $0.8-17.0$ & $7.9 \pm 3.5$ & 8.1 \\
Daily $\mathrm{SO}_{2}(\mathrm{ppb})$ & 7,296 & $0-54.1$ & $7.9 \pm 6.2$ & 6.4 \\
\hline
\end{tabular}


co-efficient $=0.46$ ). Only 4,204 observation days were available for $\mathrm{PM}_{10}$ because of missing data; one county had measures every 6 days, and two counties had a 2-year gap (from mid1998 to mid-2000) with no PM $_{10}$ data.

Mean 6-week exposure models. Table 3 displays estimates of the association of mean 6-week $\mathrm{PM}_{10}$ and $\mathrm{SO}_{2}$ exposure and risk for preterm delivery. Risk for preterm birth increased with exposure to mean 6-week $\mathrm{PM}_{10}$ $\left(\mathrm{RR}=1.07 ; 95 \% \mathrm{CI}, 0.98-1.18\right.$ per $50-\mu \mathrm{g} / \mathrm{m}^{3}$ increase in $\mathrm{PM}_{10}$ ), offsetting by the total number of gestations at risk, and adjusting for county-specific long-term trends and copollutants $\left(\mathrm{CO}, \mathrm{NO}_{2}\right.$, and $\left.\mathrm{SO}_{2}\right)$. The RRs for the two higher $\mathrm{PM}_{10}$ exposure quarters were slightly elevated, but there was no clear evidence of a strictly monotonic dose-response relationship between 6 -week $\mathrm{PM}_{10}$ exposure and preterm delivery in the quartile analysis.

An increased risk for preterm delivery was also estimated in relation to mean 6-week $\mathrm{SO}_{2}$ (adjusted RR $=1.15$; 95\% CI, $1.00-1.32$ per $15 \mathrm{ppb}$ increase in $\mathrm{SO}_{2}$ ). There was a suggestion of a monotonic dose-response relationship between $\mathrm{SO}_{2}$ and risk for preterm delivery.

Acute effects (daily) exposure models. Among the 1-day acute time windows examined, preterm birth was most strongly associated with $\mathrm{PM}_{10}$ levels using a 2-day lag (adjusted RR $=1.10$; 95\% CI, 1.00-1.21 per $50 \mu \mathrm{g} / \mathrm{m}^{3}$ ) and a 5-day lag (adjusted RR = 1.07; $95 \%$ CI, $0.98-1.18$ per $50 \mu \mathrm{g} / \mathrm{m}^{3}$ ) (Figure 1).

For $\mathrm{SO}_{2}$, the lag with the strongest association was 3 days $(\mathrm{RR}=1.07 ; 95 \% \mathrm{CI}$, $0.99-1.15$ per $15 \mathrm{ppb}$ ) (Figure 2).

\section{Discussion}

We observed an increased risk for preterm delivery during the last 6 weeks of pregnancy with exposure to $\mathrm{SO}_{2}$ and $\mathrm{PM}_{10}$. Our point estimates are similar to those reported in the literature, and the widths of our CIs compare

Table 3. RRs and $95 \% \mathrm{Cls}$ for preterm birth and exposure to $\mathrm{PM}_{10}$ and $\mathrm{SO}_{2}$ in the 6 weeks preceding birth in four Pennsylvania counties, 1997-2001.

\begin{tabular}{lcl}
\hline Pollutant & Range & $\mathrm{RR}^{\mathrm{a}}(95 \% \mathrm{Cl})$ \\
\hline $\mathrm{PM}_{10}\left(\mu \mathrm{g} / \mathrm{m}^{3}\right)$ & & \\
$\begin{array}{l}\text { Continuous } \\
\text { (per } 50-\mu \mathrm{g} / \mathrm{m}^{3} \text { increase) }\end{array}$ & & $1.07(0.98-1.18)$ \\
First quarter & $8.7-21.1$ & 1.00 \\
Second quarter & $21.1-26.0$ & $1.00(0.95-1.05)$ \\
Third quarter & $26.0-31.6$ & $1.04(0.99-1.09)$ \\
$\quad$ Fourth quarter & $31.6-68.9$ & $1.03(0.98-1.08)$ \\
$\mathrm{SO}_{2}$ (ppb) & & $1.15(1.00-1.32)$ \\
$\quad$ Continuous & & \\
$\quad$ (per 15-ppb increase) & & \\
First quarter & $0.8-4.9$ & 1.00 \\
$\quad$ Second quarter & $4.9-8.1$ & $1.02(0.97-1.06)$ \\
Third quarter & $8.1-10.6$ & $1.04(0.98-1.10)$ \\
Fourth quarter & $10.6-17.0$ & $1.06(0.99-1.14)$ \\
\hline
\end{tabular}

aRR offsetting by gestations at risk and adjusting for longterm seasonal preterm birth trend and co-pollutants $\left(\mathrm{NO}_{2}\right.$, $\mathrm{CO}$, and $\mathrm{SO}_{2}$ in the $\mathrm{PM}_{10}$ analysis, $\mathrm{PM}_{10}$ in the $\mathrm{SO}_{2}$ analysis). favorably with those for previously reported estimates. The estimated number of excess preterm births that can be attributed to these pollutants, computed as the number needed to treat (NNT) (Cordell 1999), was approximately 1 excess preterm birth for every 125 births exposed to a $50 \mu \mathrm{g} / \mathrm{m}^{3}$ increase in $\mathrm{PM}_{10}$, and 1 excess preterm birth for every 58 births exposed to a 15 ppb increase in $\mathrm{SO}_{2}$. To compute the NNT, we assumed that the baseline prevalence approximated the overall prevalence of preterm birth in the study population [risk among unexposed $\left(R_{0}\right)=$ $0.114]$ and given a $R R=1.07$ for $\mathrm{PM}_{10}$, the risk among exposed $\left(R_{1}\right)=0.122$, the RD (risk difference $)=0.008$, and the NNT $=1 / 0.008=$ 125. In the week before birth, the strongest associations were observed with a 2-day and 5-day lag for $\mathrm{PM}_{10}$ and a 3-day lag for $\mathrm{SO}_{2}$.

Several hypothesized mechanisms support biologic plausibility of an effect of air pollution on preterm birth. Two mechanisms potentially act through distinct pathways operating at the end of pregnancy. Changes in blood viscosity due to inflammation as a result of exposure to $\mathrm{PM}$ and $\mathrm{SO}_{2}$ have been observed (Peters et al. 1997). Inflammation has also been related to preterm delivery and could be associated with inadequate placental perfusion (Knotternus et al. 1990; Zondervan et al. 1987). This pathway could explain an acute effect of air pollution on preterm birth, evidence for which was observed for both $\mathrm{PM}_{10}$ and $\mathrm{SO}_{2}$.

A second possible pathway is a more longterm process that involves maternal infection during pregnancy. Although air pollution does not directly cause maternal infections, exposure to specific pollutants may impair immune function, which could enhance susceptibility to infection (Gardner 1984; Hertz-Picciotto et al. 2002). Subtle changes in the immune system could result in changes among vaginal flora, which promote vaginal pathogens associated with bacterial vaginosis, a risk factor for preterm birth (Minkoff et al. 1984). Studies also show associations between preterm labor

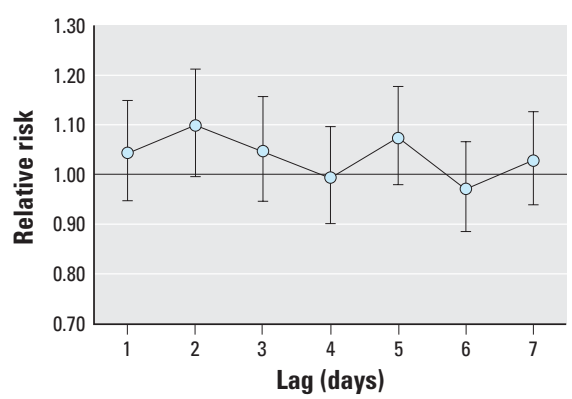

Figure 1. RRs and $95 \% \mathrm{Cls}$ for preterm birth per $50-\mu \mathrm{g} / \mathrm{m}^{3}$ increase in $\mathrm{PM}_{10}$, lagged 1-7 days before birth, offsetting by the number of gestations at risk and adjusting for long-term trends, temperature, dew point temperature, day of the week, and copollutants $\left(\mathrm{NO}_{2}, \mathrm{CO}\right.$, and $\left.\mathrm{SO}_{2}\right)$ in four Pennsylvania counties, 1997-2001. and delivery and systemic maternal infections, such as pneumonia and pyelonephritis, as well as more local infections, such as intra-amniotic and urinary infections (Benedetti et al. 1982; Cunningham et al. 1973; Fan et al. 1987; Guzick and Winn 1985; Madinger et al. 1989; Moller et al. 1984; Naeye and Peters 1980; Pankuch et al. 1984; Regan et al. 1981; Romero and Mazor 1988). This pathway could explain the associations observed in this study for both $\mathrm{PM}_{10}$ and $\mathrm{SO}_{2}$ in the 6 weeks before birth.

Our results are consistent with a number of prior studies of $\mathrm{PM}_{10}$ and $\mathrm{SO}_{2}$ exposure and preterm birth, all of which examined spatial gradients in exposure. A retrospective cohort study of 97,158 infants born between 1989 and 1993 in Southern California found an increase in risk of preterm delivery with exposure to $\mathrm{PM}_{10}$ during the 6-week period preceding birth $(\mathrm{RR}=1.20$; 95\% CI, 1.09-1.33 per $50-\mu \mathrm{g} / \mathrm{m}^{3}$ increase in $\mathrm{PM}_{10}$ ) (Ritz et al. 2000). This study did not investigate or control for the effect of $\mathrm{SO}_{2}$. A population-based prospective cohort study of 25,370 Chinese women that gave birth in Beijing in 1988 found evidence of an acute effect of TSP on preterm birth in the 7 days before birth [odds ratio $(\mathrm{OR})=1.10 ; 95 \% \mathrm{CI}, 1.01-1.20]$ for each $100-\mu \mathrm{g} / \mathrm{m}^{3}$ increase in TSP (Xu et al. 1995). This study also reported evidence of an acute effect of $\mathrm{SO}_{2}$ in the 7 days before birth $(\mathrm{OR}=$ 1.21; 95\% CI, 1.01-1.45) for each $100-\mu \mathrm{g} / \mathrm{m}^{3}$ (37.5 ppb) increase in $\mathrm{SO}_{2}$. A retrospective study conducted among 126,752 singleton births in the Czech Republic during 1991 reported adjusted ORs for preterm delivery to be 1.12 (95\% CI, 0.97-1.28) and $1.24(95 \%$ CI, $1.13-1.36)$ per $50-\mu \mathrm{g} / \mathrm{m}^{3}(18.75 \mathrm{ppb})$ increase in TSP and $\mathrm{SO}_{2}$, respectively, during the third trimester of pregnancy (Bobak 2000). In Vancouver, Canada, a retrospective study of all live births between 1985 and 1998 that did not investigate or control for particles found an association between preterm birth and $\mathrm{SO}_{2}$ $(\mathrm{OR}=1.09 ; 95 \% \mathrm{CI}, 1.01-1.19$ per $5-\mathrm{ppb}$

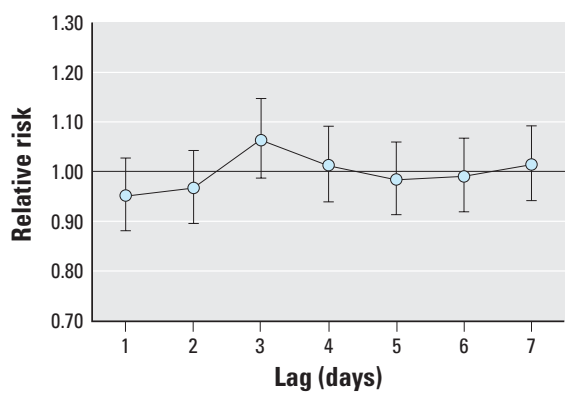

Figure 2. RRs and $95 \% \mathrm{Cls}$ for preterm birth per 15-ppb increase in $\mathrm{SO}_{2}$, lagged 1-7 days before birth, offsetting by the number of live births and adjusting for long-term seasonal trend, temperature, dew point temperature, day of the week, and copollutants $\left(\mathrm{NO}_{2}, \mathrm{CO}\right.$, and $\left.\mathrm{PM}_{10}\right)$ in four Pennsylvania counties, 1997-2001. 
increase) during the last month of pregnancy (Liu et al. 2003).

A potential limitation of these previous studies is inadequate control for confounding by individual risk factors. Birth record data do not include information on all risk factors that could potentially confound the relationship between air pollution and preterm delivery. In addition, variables that are collected may be poorly measured or recorded, particularly when they come from a birth certificate, which could lead to residual confounding in either direction of the association between air pollution and preterm birth.

By observing the population over time using time-series analysis, we could investigate the impact of air pollutants without the influence of known and unknown individual risk factors that do not vary over short periods of time. Consistency of the overall findings of our study with previous studies suggests that confounding at the individual level is probably not explaining the observed association between air pollution and preterm delivery. However, more complete control of confounding could explain the weaker associations observed in this study; this could also be caused by differences in pollution levels or sources between study locations.

Our study was efficient in that it made use of existing air pollution and birth record data. This allowed for a very large, populationbased study that is not subject to selection biases that arise when recruiting a patient population. In addition, the long study period and large population enhanced the precision of the estimated measures of effect. Given these advantages, in addition to the ease associated with using extant data sources relative to generating original data, investigation of additional health outcomes (including other birth outcomes) using this study design is advisable.

An acknowledged limitation of all studies of ambient air pollution is that measurements from stationary outdoor monitors may not represent individual exposure. Studies of air pollution and mortality, cardiovascular disease, and other respiratory outcomes have addressed this issue and report that, although relatively crude, ambient measures are often the most feasible measure of exposure in terms of cost and burden to the study participant (Samet et al. 2000). In addition, investigators project that the likely consequence of using ambient concentrations is to underestimate air pollution effects (Zeger et al. 2000).

The time-series analysis assumes that ambient pollution levels and personal exposure are often correlated over time, so although their absolute levels may be different, both will be high on a high-air-pollution day and low on a low-air-pollution day (Zeger et al. 2000). Measurement of outcomes in relation to time should therefore produce the appropriate exposure contrasts. Measurement error was probably nondifferential with respect to preterm delivery, which would most likely lead to underestimation of the true effect. Finally, studying ambient levels has advantages for informing regulations at the population level.

This study was limited to the investigation of two criteria pollutants collected by the U.S. EPA's AQS (Air Quality System 2003). The question of whether $\mathrm{PM}_{10}$ and $\mathrm{SO}_{2}$ are hazardous themselves or are markers for other hazardous airborne pollutants, such as sulfates that result from $\mathrm{SO}_{2}$ emissions in the presence of water and oxygen, fine particles $\left(\mathrm{PM}_{2.5}\right)$, or other noncriteria pollutants such as polycyclic aromatic hydrocarbons, was beyond the scope of this study and is a direction for further investigation. Some of the previous literature suggests associations between $\mathrm{CO}$ and/or $\mathrm{NO}_{2}$ and preterm birth (Bobak 2000; Liu et al. 2003; Maroziene and Grazuleviciene 2002; Ritz et al. 2000). We focused on $\mathrm{PM}_{10}$ and $\mathrm{SO}_{2}$ because the literature was the most consistent for these pollutants; however, we did perform preliminary analyses for $\mathrm{CO}$, and $\mathrm{NO}_{2}$ and our results did not support an association between these pollutants and preterm birth.

Missing data for $\mathrm{PM}_{10}$ limited the number of observation days for both the 6-week and daily acute effects analysis, reducing the precision of the effect estimates.

We limited our analyses to exposure windows at the end of pregnancy. It is plausible, however, that air pollution could interfere with development of the placenta or other processes in early fetal development that begin a path to preterm delivery. Two previous studies found an association between exposure to $\mathrm{PM}_{10} / \mathrm{TSP}$ at beginning of pregnancy (first month and first trimester) and preterm delivery (Bobak 2000; Ritz et al. 2000). One of these studies also found an association between $\mathrm{SO}_{2}$ at the beginning of pregnancy and preterm delivery (Bobak 2000); however, these results were contradicted in another study (Liu et al. 2003).

We also did not adjust for other time windows of exposure in our analyses. For example, in the model of exposure to air pollution in the 6 weeks preceding birth, we did not control for exposure to air pollution earlier in pregnancy. In addition, we did not adjust for exposure during the 7 days preceding birth. This may have limited our ability to attribute effects to a specific time window of exposure, which would help to understand the biologic mechanism for a possible effect.

Gestational age, which is difficult to measure accurately, may have been incorrectly estimated on the birth certificate. We restricted our analysis to births between 20 and 44 weeks of gestation to attempt to filter out the most serious of these errors; however, it is likely that a degree of error remains. Error in gestational age is probably not influenced by air pollution, however, thus the misclassification is likely to be non-differential with respect to exposure, which most likely led to an attenuated estimate of the true effect of air pollution on preterm delivery.

Despite limitations in our data, we observed evidence of an effect of both $\mathrm{PM}_{10}$ and $\mathrm{SO}_{2}$ on preterm delivery. The absolute increases in risk were small, with 1 or 2 excess preterm births for every 100 births exposed to a $50-\mu \mathrm{g} / \mathrm{m}^{3}$ increase in $\mathrm{PM}_{10}$ or $15-\mathrm{ppb}$ increase in $\mathrm{SO}_{2}$. However, many people live in urban centers and are chronically exposed to high levels of air pollution; if these small effects are indeed causal, the public health impact could be considerable. Additional studies in other geographical areas and time periods would be warranted. Further research to identify the critical time window(s) during pregnancy for the effect of air pollution on preterm birth, and to delineate the biologic mechanism for such an effect would also be useful.

\section{REFERENCES}

Air Quality System (AQS), Air Quality Planning and Standards, U.S. EPA. Available: http://www.epa.gov/air/data/aqsdb.html [accessed June 2003].

Akaike H. 1973. Information theory and an extension of the maximum likelihood principal. In: Second International Symposium on Information Theory (Petrov BN, Csaki F eds). Budapest, Hungary:Akademiai Kaiado.

Benedetti TJ, Valle R, Ledger WJ. 1982. Antepartum pneumonia in pregnancy. Am J Obstet Gynecol 144(4):413-417.

Berkowitz G, Pepiernik E. 1993. Epidemiology of preterm birth. Epidemiol Rev 15:414-443.

Bobak M. 2000. Outdoor air pollution, low birth weight, and prematurity. Environ Health Perspect 108(2):173-176.

Centers for Disease Control and Prevention. 1999. Preterm singleton births-United States, 1989-1996. MMWR Morb Mortal Wkly Rep 48(9):185-189.

Cooperstock M, Wolfe RA. 1986. Seasonality of preterm birth in the Collaborative Perinatal Project: demographic factors. Am J Epidemiol 124:234-241.

Cordell WH. 1999. Number needed to treat (NNT). Ann Emerg Med 33(4):433-436.

Cunningham FG, Morris GB, Mickal A. 1973. Acute pyelonephritis of pregnancy: a clinical review. Obstet Gynecol 42(1):112-117.

Dominici F, McDermott A, Zeger SL, Samet JM. 2002. On the use of generalized additive models in time-series studies of air pollution and health. Am J Epidemiol 156:193-203.

Fan YD, Pastorek JGn, Miller JMJ, Mulvey J. 1987. Acute pyelonephritis in pregnancy. Am J Perinatol 4(4):324-326.

Gardner DE. 1984. Oxidant-induced enhanced sensitivity to infection in animal models and their extrapolations to man. J Toxicol Environ Health 13(2-3):423-439.

Guzick DS, Winn K. 1985. The association of chorioamnionitis with preterm delivery. Obstet Gynecol 65(1):11-16.

Hertz-Pic ciotto I, Dostal M, Dejmek J, Selevan SG, Wegienka G, Gomez-Caminero A, et al. 2002. Air pollution and distributions of lymphocyte immunophenotypes in cord and maternal blood at delivery. Epidemiology 13(2):172-183.

Keller GA, Nugent RP. 1983. Seasonal patterns in perinatal mor tality and preterm delivery. Am J Epidemiol 118:689-698.

Knotternus JA, Delgado LR, Knipschild PG, Essed GG, Smits F. 1990. Haematologic parameters and pregnancy outcome. A prospective study in the third trimester. J Clin Epidemiol 43:461-466.

Kramer MS. 1987. Determinants of low birth weight: methodological assessment and meta-analysis. Bull World Health Organ 65:663-737.

Liu S, Krewski D, Shi Y, Chen Y, Burnett RT. 2003. Association between gaseous ambient air pollutants and adverse pregnancy outcomes in Vancouver, Canada. Environ Health Perspect 111:1773-1778.

Madinger NE, Greenspoon JS, Ellrodt AG. 1989. Pneumonia 
during pregnancy: has modern technology improved maternal and fetal outcome? Am J Obstet Gynecol 161(3):657-662

Maroziene L, Grazuleviciene R. 2002. Maternal exposure to low-level air pollution and pregnancy outcomes: a population-based study. Environ Health 1(1):6-13.

Martin JA, Hamilton BE, Ventura SJ, Menacker F, Park MM. 2002. Births: final data for 2000. Natl Vital Stat Rep 50(5):1-101.

Matsuda S, Kahyo H. 1992. Seasonality of preterm births in Japan. Int J Epidemiol 21:91-100.

Minkoff H, Grunebaum AN, Schwartz RH, Grunebaum AN, Schwarz RH, Feldman J, et al. 1984. Risk factors for prematurity and premature rupture of membranes: a prospective study of the vaginal flora in pregnancy. Am J Obstet Gynecol 150:965-972.

Moller M, Thomsen AC, Borch K, Dinesen K, Zdravkovic M. 1984. Rupture of fetal membranes and premature delivery associated with group $B$ streptococci in urine of pregnant women. Lancet 2(8394):69-70.
Naeye RL, Peters EC. 1980. Causes and consequences of premature rupture of fetal membranes. Lancet 1(8161):192-194.

NOAA/NCDC. 2003. Online Climate Data, National Climate Data Center. Available: http://www.ncdc.noaa.gov/ol/climate/ climatedata.html [accessed August 2003].

Pankuch GA, Appelbaum PC, Lorenz RP, Botti JJ, Schachter J, Naeye RL. 1984. Placental microbiology and histology and the pathogenesis of chorioamnionitis. Obstet Gynecol 64(6):802-806.

Peters A, Doring A, Wichmann HE, Koenig W. 1997. Increased plasma viscosity during an air pollution episode: a link to mortality? Lancet 349:1582-1587.

Regan JA, Chao S, James LS. 1981. Premature rupture of membranes, preterm delivery, and group $B$ streptococcal colonization of mothers. Am J Obstet Gynecol 141(2):184-186.

Ritz B, Yu F, Chapa G, Fruin S. 2000. Effect of air pollution on preterm birth among children born in Southern California between 1989 and 1993. Epidemiology 11(5):502-511.
Romero R, Mazor M. 1988. Infection and preterm labor. Clin Obstet Gynecol 31:553-584.

Samet J, Dominici F, Zeger S, Schwartz J, Dockery D. 2000. The National Morbidity, Mortality, and Air Pollution Study, Part I: Methods and Methodologic Issues. Report No. 94, Part I. Boston:Health Effects Institute.

Xu X, Ding H, Wang X. 1995. Acute effect of total suspended particles and sulfur dioxides on preterm delivery: a communitybased cohort study. Arch Environ Health 50(6):407-415.

Zeger SL, Thomas D, Dominici F, Samet JM, Schwartz J, Dockery D, et al. 2000. Exposure measurement error in time-series studies of air pollution: concepts and consequences. Environ Health Perspect 108:419-426.

Zondervan HA, Oosting J, Hardeman MR, Smorenberg-Schoorl ME, Treffers PE. 1987. The influence of maternal whole blood viscosity on fetal growth. Eur J Obstet Gyneco Reprod Biol 25:187-194. 